\title{
Portage home based programme for preterm infants did not provide a developmental advantage at 2 years of age
}

\author{
Avon Premature Infant Project. Randomised trial of parental support for families with very preterm children. Arch Dis Child Fetal \\ Neonatal Ed 1998 Jul;79:F4-11.
}

\section{Question}

In preterm infants, is a home based developmental educational programme (Portage) effective in improving developmental scores at 2 years?

\section{Design}

2 year randomised controlled trial.

\section{Setting}

2 hospitals in Bristol, UK.

\section{Patients}

Participants were families of infants who were born at a gestational age of $<33$ weeks to mothers who were resident in the Bristol area and whose first language was English. Of 328 infants who were randomised, the families of 309 surviving infants (mean gestational age $31 \mathrm{wk}, 57 \%$ boys) gave consent.

\section{Intervention}

Infants were stratified by gestation $(<28 \mathrm{wk}$ and $\geqslant 28 \mathrm{wk})$ and hospital of care and allocated between the 7 th and 10th day after birth to a Portage group $(n=116)$, parent advisor group $(n=106)$, or control group $(n=106)$. Portage involved detailed developmental teaching by trained research nurses and introduced the parent to aspects of their child's developmental progress. The parent advisor group received seminars and individual and group work from research nurses using a supportive counselling model to control for the support aspect of Portage. Both interventions were delivered as home visits, weekly at first and decreasing to monthly by 2 years.

Main outcome measure

2 year development (Griffiths Mental Development Scale).

\section{Main results}

The study had sufficient power to detect a 5 to 6 point difference in Griffiths scores between groups at 2 years. The mean Griffiths score for Portage was 96.8, for parent advisor 95.9, and for preterm control 92.9. The scores did not differ between the 3 preterm groups (table). All 3 were lower than that of a reference group of 109 term infants (mean Griffith score 102). When children with disability were excluded (33 preterm children), the lack of difference between the 3 groups was maintained, but only the preterm control group had lower Griffiths scores than the term reference group (mean difference 4.7 points, $95 \%$ CI 1.6 to 7.8). A post-hoc analysis revealed that the greatest effect of Portage occurred in children whose birth weight was $<1251 \mathrm{~g}$ or who had an abnormal cerebral ultrasound scan.

\section{Conclusion}

Use of the Portage home based developmental training programme for the families of preterm infants did not improve developmental performance in the children by 2 years of age.

Difference between Portage, parent advisor, and preterm control groups for Griffiths scores at 2 years

\begin{tabular}{ll}
\hline Comparison & Mean difference $(95 \%$ CI) \\
\hline Portage $v$ parent advisor & $0.9(-3.6$ to 5.4$)$ \\
Portage $v$ preterm control & $3.9(-1.2$ to 9.0$)$ \\
\hline
\end{tabular}

Sources of funding: Action Research; Crookes Health Care; Nutricia; Milupa.

For correspondence: Prof N Marlow, Department of Child Health, University Hospital, Queens Medical Centre, Nottingham NG7 2UH, UK. Fax +44 (0)1159709382.

\section{Commentary}

The Portage programme is a well established early intervention for young children with developmental disabilities. It is popular with parents, professionals, and policy makers because it is home based, provides practical advice, complements medical treatment, and is provided largely by volunteers thus making it relatively inexpensive.

North American studies have shown modest but important benefits of programmes such as Portage. ${ }^{1}$ However, the high risk infants in those studies are not typical of the average preterm graduate of most neonatal units. By taking a population approach, the study from the Avon Premature Infant Project provides more generalisable results. Another strength of this study design is that it separates the social support effects of Portage home visitors from the developmental effects of the programme.
The differences between the groups were neither statistically significant nor clinically important, suggesting that intensive early developmental stimulation for preterm infants is unlikely to be worth investing in. A host of post-hoc analyses are presented which show, if nothing else, how "the best laid schemes o' mice and researchers gang aft a-gley." The most serious misfortune being that, despite randomisation, the control group was socially more advantaged than the 2 intervention groups. Controlling for this discrepancy showed a small but statistically significant benefit of both interventions. The authors also emphasise that the greatest effects were seen among the smallest infants and those with brain injuries. Post-hoc subgroup analyses, however, provide poor quality evidence. Nevertheless, there are 3 reasons for not dismissing early developmental stimulation just yet. Many longer term follow up studies of preterm infants show that mild to moderate learning, attention, and physical disabilities are not identified until school age. ${ }^{23}$ A Griffiths assessment at age 2 is a crude and insensitive measure of developmental potential. Finally, studies suggest that the effects of early intervention may be amplified over many years. ${ }^{4}$ Long term follow up of this study cohort will be essential.

Richard Reading, MD, FRCPCH Norfolk and Norwich Hospital

Norfolk, UK

1 McCormick MC, McCarton C, Tonascia J, et al. J Pediatr 1993;123:527-33.

2 Pharoah PO, Stevenson CJ, Cooke RW, et al. Arch Dis Child 1994;70:264-70.

3 Pharoah PO, Stevenson CJ, Cooke RW, et al. Arch Dis Child 1994;70:271-4.

4 Hertzman C, Wiens M. Soc Sci Med 1996;43: 1083-95. 